December 2016

\title{
Evaluating library service quality at the Aga Khan University library: Application of a total quality management approach
}

Nasra Gathoni

Aga Khan University, nasra.gathoni@aku.edu

Thomas Van der Walt

University of South Africa

Follow this and additional works at: https://ecommons.aku.edu/libraries

Part of the Library and Information Science Commons

\section{Recommended Citation}

Gathoni, N., Walt, T. V. (2016). Evaluating library service quality at the Aga Khan University library: Application of a total quality management approach. Journal of Librarianship and Information Science, 1-14.

Available at: https://ecommons.aku.edu/libraries/28 


\section{Evaluating library service quality at the Aga Khan University library: Application of a total quality management approach}

Journal of Librarianship and Information Science

(C) The Author(s) 2016 Reprints and permissions: sagepub.co.uk/journalsPermissions.nav DOI: 10.1 I77/0961000616679725 journals.sagepub.com/home/lis

\author{
Nasra Gathoni
}

Aga Khan University, Kenya

Thomas Van der Walt

University of South Africa, Pretoria, South Africa

\begin{abstract}
The purpose of this paper is to report on an investigation of the service quality of the Aga Khan University library in Kenya. The total quality management philosophy which forms the basis of this report has been demonstrated by the use of SERVQUAL, a userbased assessment tool, in the evaluation of service quality. The research was conducted among 123 Aga Khan University library users - nursing and medical faculty and nursing and medical students - with an aim to investigate the quality of its services based on the satisfaction of library users with the services and as expressed by and based on users' expectations and perceptions. The data was gathered through the SERVQUAL structured questionnaire and a 63\% response rate was realized. The findings generally established that the expectations of Aga Khan University library users are higher than their perceptions. The results also show that there are service quality gaps in a number of services offered by the library.

This research is deemed important as there is lack of information showing libraries in Kenya having involved library users in service quality evaluation through the use of objective and user-based tools. Thus this paper may lead to libraries in Kenya embracing objective measurement tools for the evaluation of library service quality. It is hoped that this article will contribute to a better understanding of philosophies such as total quality management in an academic library environment in developing countries, users' expectations and perceptions of quality.
\end{abstract}

\title{
Keywords
}

Kenya, library service quality, library service quality assessment, SERVQUAL, total quality management

\section{Introduction}

Total quality management (TQM) is considered a management approach and philosophy that fosters the culture and attitude of an organization in providing customers with quality services and products that satisfy their needs (Stark, 1998). It embraces the viewpoint that there is a need for continuous improvement of systems and processes regarding products and services in an organization (Ho, 1995: 51). Various studies (e.g. Ling-Yun and Hai-Kang, 2005: 1362; Morrow, 1997: 365; Mehra et al., 2001: 866) have indicated the core principles of TQM as being customer focused and seeking customer satisfaction by producing services and goods of high quality, continuous improvement and teamwork which can be achieved by ensuring regular feedback from the customer. The regular feedback from the customer provides information on the customer's needs and expectations. Kumbar (2004) stresses the importance of continuously being responsive to the demands and needs of a customer.

Though there are a number of TQM frameworks available such as Demings' 14 points, Crosby's 14 steps and Juran's breakthrough strategy, there is still confusion about defining the main TQM principles (Morrow, 1997: 363). Despite the difficulty in identifying one definition for TQM, Wang (2006: 607) attempts to provide a clear

\section{Corresponding author:}

Nasra Gathoni, Aga Khan University, PO Box 30270, Nairobi, Kenya. Email: nasragathoni@gmail.com 
and comprehensive explanation by looking at the meaning of each of the words: total, quality and management. According to Wang (2006: 607) the word total shows that management is no longer based on individual sections or departments handling only their section and not being concerned about the other sections. The word total depicts moving away from old management methods and emphasizing the need for all those in an organization to be aware of "the whole working process". The word quality which is predominant in the TQM philosophy emphasizes the need to identify customers' needs and expectations and to ensure that the customer is satisfied. The word management advocates for an approach which requires one to continue improving services through management in line with the ever changing needs of the customers.

The customer focus and ensuring customer satisfaction through the provision of quality services and goods can be traced back to the American, W. Edwards Deming, who after the Second World War developed the concept to ensure the production of quality goods and improve the supply of services. Deming was approached by the Japanese for training on quality improvement in the period 1948-1959 in order to improve productivity and enhance quality of life which had been destroyed by the war (Zhan and Zhang, 2006: 344). The TQM philosophy has its principles oriented to customer service and quality improvement and has been credited with transforming Japan into a leading economy after the Second World War (Wang, 2006: 606).

Quality has already been identified above as predominant in the TQM philosophy. Another important issue is to identify how organizations have measured quality or applied methods to ensure that the requirements of customers are met. There are various techniques for measuring TQM efforts such as time series (predicting future levels from past figures), use of a control chart (a tool that helps to identify and control processes), cost of quality (determines cost of producing a quality product) and awards such as the Malcolm Baldrige National Quality Award that recognizes US organizations in the business, health care, education and non-profit sectors for performance excellence on an annual basis (Besterfield et al., 2003: 173). Besides the aforementioned techniques, there are internationally recognized standards which were developed for evaluating quality, for example, the International Organization for Standards (ISO) 9000 standard. Despite the fact that the ISO standardization has been widely accepted and applied to both manufacturing and service industries (Besterfield et al., 2003: 253; Ho, 1995: 6; Kujala, 2002: 45; Zhan and Zhang, 2006: 345), previous studies have emphasized the importance of developing and applying models or tools that could be applied more specifically to the quality of service in academic libraries (Kiran, 2010: 261).

\section{International TQM applications in academic libraries}

Though TQM was initially applied to manufacturing functions and operations, studies show that it is also applied by service organizations such as hospitals, hotels and schools (Mehra and Ranganathan, 2008: 916; Moghaddam and Moballeghi, 2008: 912; Powell 1995: 16). As service organizations, libraries have endeavoured to apply TQM for the improvement of library services as manifested in publications by Pilling (1996), Khurshid (1997), Tam (2000), Alemna (2001), Whitlatch (2003), Ling-Yun and Hai-Kang (2005) and Wang (2006). These aforementioned publications describe attempts made to implement TQM to improve library services at various institutions.

One factor that may, however, hinder the implementation of TQM in academic libraries is the original reason why TQM came into being, namely to improve profits. Academic libraries are usually non-profit-making organizations, providing most of their services free of charge. Nonetheless, with serious financial constraints caused by high inflation and reducing budgets they are still required to continue providing services and thus libraries are now faced with the challenge of ensuring that services provided are as cost effective as possible (Alemna, 2001: 266; Nitecki, 1996: 181). Furthermore, it is expected of these service organizations to provide services that meet or exceed the various information needs and expectations of their users. This is in line with the TQM philosophy, as feedback from users would provide knowledge that would be used to provide appropriate quality services. This philosophy has not been a common feature in libraries (Alemna, 2001: 266) and there is need for libraries to embrace it through a culture of striving to identify users' current and future expectations (Mehra et al., 2001: 866). Tuomi (2001: 3) is of the opinion that by embracing these aspects of TQM, academic libraries would move away from the traditional approach of describing quality in terms of the library collection and number of users that is now considered obsolete. In regards to evaluating service quality, Parasuraman et al. (1988: 14) identified five service quality variables namely tangibles, reliability, responsiveness, assurance and empathy. These variables show the dimensions through which a user would form an expectation and perception of a service. In evaluating service quality therefore, the five dimensions should be evaluated and this is possible through the application of developed assessment tools.

From the earlier discussion, it is apparent that libraries in developed countries have attempted to apply various aspects of TQM since the late 1980s (Moghaddam and Moballeghi, 2008: 916). In contrast, in developing countries the application of TQM is only evident in a few countries such as India and Pakistan. In Kenya, the TQM philosophy has not been embraced in libraries. A study by Ondari-Okemwa (2000: 264) found that most library staff 
were not aware of the TQM philosophy and they were reluctant to adapt and implement it as they did not know what it involved. Despite this, the concept of quality is not new in the library environment as it is a basic requirement that all libraries strive to achieve. Nevertheless, libraries need to change the way they have evaluated the quality of services. In Kenya for example attempts at assessing service quality in libraries have been based on collection statistics, circulation statistics, the number of users visiting the library, opening hours and on national standards set by the Kenyan Commission for University Education (CUE) formerly Commission for Higher Education (CHE) -with which academic libraries should comply. These CUE standards thus serve as an evaluation tool for higher education institutions including academic library services and facilities (CUE, 2013). The essence of the standards is to have academic libraries maintain a certain level of quality. Such standards are, however, input based, for example the number of computers per student, number of journals in the library in relation to the number of students, and these standards are not adequate. According to Sahu (2007: 234) libraries need to adopt other methods to evaluate library service quality as opposed to the traditional user statistics and input-based measures. The need for user-based evaluation in the library environment has given recognition to user-based assessment tools such as SERVQUAL and LIBQUAL among others (Yu et al., 2008: 512). Although there has been an increase in the assessment of library service quality in countries in Europe, America and Asia using the aforementioned assessment tools, libraries in Kenya have not yet adopted this approach. This brings an urgent need for libraries in Kenya to address how they are evaluating service quality especially in these times where libraries are experiencing financial and resource constraints. In line with the TQM philosophy, libraries in Kenya need to ensure that the user is at the centre of all its activities and this can be achieved by embracing user-based assessment tools in the evaluation of service quality.

\section{Service quality}

There has been significant interest in the measurement of service quality especially in the library environment (Jayasundara, 2011:25). In an era of exponential technology growth, economic crisis, user behaviour change and as users continue to portray more sophisticated needs, it is becoming essential to ensure that services provided are of high quality. The term "quality" however can be an elusive term with varying definitions. IFLA has defined quality as "fitness for purpose" while Tuomi (2001) defines quality as features or products that meet the needs of the users. Due to the complexity of defining the term quality, there has been a lot of debate on how to define quality in service organizations, i.e. service quality. This is because service is intangible and thus more complex. According to Somaratna and Peiris (2011) and Jayasundara (2011) this complexity is due to the fact that service quality begins with design and is present through the whole process of delivery and performance, with assessment during the delivery process. Similarly Brysland and Curry (2001: 391) having considered various definitions concluded that service quality refers to when an intangible something is provided in such a way that the customer is pleased. From the various definitions, it can therefore be argued that service quality is essentially about ensuring that the customer is satisfied. Though service quality is a difficult concept to define there seems to be a general consensus that service quality should be determined by the customer. This means that the customer perception of the service defines and measures service quality (Jayasundara, 2011: 26). According to Somaratna and Peiris $(2011: 1)$ this is the most recognized definition of service quality for the reason that a service should meet the needs of the customer it is meant for and hence it is only fitting for the intended customer to indicate whether the needs have been met. Since the expectation of a service may influence how a service is perceived, service quality can therefore be conceptualized as the discrepancy between the user's expectation and their perceptions. This has been a widely accepted definition which is founded on the gap theory whose origin can be traced to Parasuraman et al. in 1994 (Jayasundara, 2011: 26; Somaratna and Peiris, 2011: 1).

The ever rising expectations of users, user information behaviours and the complexity involved in providing information are some of the reasons that have contributed to the need for libraries to address whether the services provided meet the needs of the users. Furthermore, rapid technological advancement and increasing cost of information have also added to expectations of the parent organization and more so of the users. As a result, libraries are therefore required to review the traditional methods of evaluating their services in order to fulfil user needs as well as show relevance, transparency and accountability (Sahu, 2006: 234). The traditional methods libraries have used over the years are no longer adequate. Describing the quality of library service through the size of collection or opening hours "no longer fulfils the goals for successfully meeting he users' demands for information" and are thus deemed inadequate (Sahu, 2007:234).

In view of the various definitions of quality it is important to note that the critical issue alluded to is the necessity to meet the needs of the users thus leading to customer satisfaction. Satisfaction is therefore a key factor in service quality. Other key factors that are also depicted in the definitions of service quality are "satisfaction", "expectation" and "perception".

\section{Service quality variables}

Service quality should essentially be determined by evaluating the variables that a customer would use to determine 
quality. In an attempt to conceptualize service quality, Parasuraman et al. in 1984 identified four gaps that can affect quality in an organization. They also identified variables that users apply to determine quality. The authors argued that within each variable a user's expectation and perception of the service should be met. A quality problem is therefore caused if there is a gap between the expectation and the perception of the user (Parasuraman et al., $1985,1988)$. Based on extensive research within various service industries, Parasuraman et al. (1985: 46) concluded that customers use the same dimensions to determine whether a service is of quality or not. The research revealed that the same criteria are used by consumers regardless of the type of service (Parasuraman et al., 1985: 45). Their study identified service quality variables, that is, "dimensions that consumers use in forming expectations about and perceptions of services" (p. 49). The study also showed the "determinants of perceived service quality". These dimensions are important in the conceptualization of service quality construct and have led to the development of tools that can be used to measure the construct (Parasuraman et al., 1988: 14).

\section{User-based service quality assessment tools}

According to Parasuraman et al. (1988: 17) service quality is "viewed as the degree and direction of discrepancy between customer perception and expectation". Brysland and Curry (2001: 391), having looked at various definitions concluded that service quality is something intangible that is provided in such a way that the customer's needs are met therefore resulting in customer satisfaction. Assessing the quality of services is therefore a complex domain due to the intangible nature of a service. A study by Lincoln (2002: 15) clearly explains the complexity of service by attempting to bring out different meanings. In her paper she articulates this complexity as follows: service is not performed but is a performance; service is not dispensed but enacted; service between the provider and the recipient is an intricate process where the nature of the service may change due to eternal or external factors and also the behaviour of the recipient of the service has changed and may continue to change.

All these dimensions have made the conceptualization and also the measurement of service quality very elusive (Carman, 1990: 33). Assessing the quality of services and specifically library services has therefore over the years been a major area of concern leading to a lot of research in various sectors and has subsequently gained significant momentum (Ladhari, 2008:65; Seth et al., 2005: 913). This has led to the development of various service quality assessment tools such as SERVQUAL, LibQUAL+ among others. Though there are many assessment tools, this article was based on use of SERVQUAL, a widely used tool in various service sectors and also one that has been researched extensively for validity (Crossno et al., 2001: 170; Derfert-Wolf et al., 2005: 4; O'Neill et al., 2001: 405; Shi and Levy, 2005: 268; Shoeb and Ahmed, 2009: 194; Yu et al., 2008: 516).

SERVQUAL. SERVQUAL is a measurement tool that was developed to measure users' expectations and perceptions against specified quality dimensions (Parasuraman et al., 1985, 1988). The tool was developed based on the gap theory whereby high quality service is achieved by closing the gap between users' expectations and perceptions. It was derived from the notion that there must be a balance between expectations and perceptions of the users in order to deliver high quality services (Tuomi, 2001). The SERVQUAL instrument is therefore based on the assumption that if a negative score is obtained this would mean that the performance is below expectation, translating into a low service quality perception. If a positive score is obtained this would then mean that the performance exceeds expectation, translating into high service quality (Robinson, 1999).

First proposed in 1985 by Parasuraman et al., SERVQUAL was later developed and revised in 1988 following empirical tests by the aforementioned authors (Lee et al., 2004: 218). The initial SERVQUAL consisted of 10 dimensions of service quality namely: (1) reliability, (2) responsiveness, (3) competence, (4) credibility, (5) access, (6) courtesy, (7) security, (8) communication, (9) understanding the customer and (10) tangibles. It was later refined to the final 22 -item scale by reducing the 10 dimensions to five, namely: (1) tangibles, (2) reliability, (3) responsiveness, (4) assurance and (5) empathy (Jayasundara 2011: 39; Shoeb 2009: 2). The developers argued that the items retained are common to service organizations regardless of the service offered.

In addition to the above mentioned modification of SERVQUAL it is important to note that the developers of SERVQUAL also recommended rewording of items to the context in which it is being applied and especially whereby a single service is being investigated (Parasuraman et al., 1988: 19). This recommendation was applied in a study undertaken in Finland by Tuomi (2001: 10) where the question on the tangible dimensions of employees' neatness was removed. This was because it was considered by library staff and researchers as not being important as it concentrated on factors that they termed superficial.

From the above discussion, it is evident that the expectation and perception of the users are two critical concepts in a service. In addition, ensuring there is no gap between the two translates into quality services and this forms the basis of SERVQUAL. Though SERVQUAL may have its weaknesses, its major strength is that it is an instrument that has been empirically tested and found to be valid. The reliability and validity of SERVQUAL has been shown in the study by Parasuraman et al. (1988: 24) which discussed 
the development of the instrument and showed consistently high reliabilities "across all four samples". The reliability of the tool was shown by the above mentioned study through the use of various statistical methods such as total scale reliability of linear combination as well as pair wise correlation among the five factors. The study showed the total scale reliability of linear combination in each of the four instances as being close to 0.9 and further verification of its reliability through pair wise correlation among the five factors found the average was .35 following oblique rotation.

Due to its generic nature, it is recommended that SERVQUAL should be used on a regular basis for comparative purposes (Brysland and Curry, 2001: 323; Shahin, 2006). This means that the SERVQUAL instrument should be administered repeatedly in order to ascertain the true picture of service quality. Studies have shown that the expectation and perceptions of users of a service may change following long use of the service. It is also necessary to use this tool on a regular basis because the level of the services provided may change and user expectations may also change. Peters (1999: 6) observes that "when expectations are regularly exceeded, a new expectation benchmark is set". Another example of users' needs changing over time is observed in the study by Carman (1990: 49) which measured students' expectations at the beginning of the school term and recorded the perceptions of the students five weeks later. He found that the students' assessment of quality was different five weeks later because expectation changes with familiarity.

This observation can further be explained by an example of a document delivery service. For example, if a user requests an article and the turnaround time for document delivery is three days, but the user receives the article in two days, he would be satisfied with the service. This would be because the service provided exceeded his expectation. But if the users continue to receive articles within two days, after many requests the users will eventually come to expect it because the users' expectations have now changed and the expectation benchmark is higher. This illustrates the complexity of defining service quality and also measuring service quality.

SERVQUAL has been recommended as an instrument which would assist decision makers in directing energies to the right areas in an attempt to improve the services. Data from a survey using SERVQUAL can also suggest priority areas for training staff and for solving problems which may arise from staff assumptions of what users like or can identify services offered in a manner that does not meet users' needs (Nitecki, 1996: 185). Use of an instrument such as SERVQUAL can also be justified because the most important aspect of quality service is identifying the expectations of the users (Brysland and Curry, 2001: 393). Furthermore, application of an assessment tool such as SERVQUAL would be in line with the
TQM philosophy as it is a user-based tool evaluating quality from the users' point of view.

\section{Service quality at the Aga Khan University library}

The Aga Khan University (AKU), Kenya, is located in Nairobi, the capital city of Kenya. It is a private, not-forprofit teaching institution committed to providing the best possible option for the diagnosis of disease and team management of patient care, fortified by the highest doctor/ patient and nurse/patient ratios and support services in the region (Aga Khan Development Network, 2007). It has two faculties in nursing and medicine; the Faculty of Nursing offers an undergraduate degree course in nursing $(\mathrm{BScN})$, while the Faculty of Medicine offers postgraduate medical education (PGME).

In an effort to evaluate service quality at Aga khan library has continued to carry out sporadic surveys based on user statistics and also according to the stipulated CUE standards. Some of the statistics collected over the years include borrowing statistics, number of users visiting the library, and number of users using online resources. For example, a survey carried out in 2011 showed $69 \%$ of the respondents were not using online resources because they were not aware of them while $31 \%$ indicated poor connectivity as the reason for not using online resources (Aga Khan University Library, 2011: 10). This approach has been combined with occasional user score cards whereby users are required to rate various service areas from poor to excellent. These statistics are, however, not interpreted meaningfully. For instance, would a library with 30,000 books be perceived to have a better service quality than one with 10,000 books? If 200 people visit the library, where is the indicator that the users' needs and/or expectations were met? These questions show the complexity of evaluating library service quality and also the need for libraries to embrace user-based assessment tools.

Like any other academic library in Kenya the Aga Khan University (AKU) library is faced with the challenge of ensuring that quality services are provided to the different user groups. The challenge is as a result of various factors such as high inflation causing the library to be under pressure to adjust to the increasing cost of providing library services. Other factors include advancement of technology and demand from users for more sophisticated service delivery. The AKU library has also experienced reduced budgets over the years and yet is still expected to continue to provide all essential services. Furthermore, the cost of providing library services has continued to escalate at an alarming rate (Awan et al., 2008: 51; Kavulya, 2006: 29; Research Information Network, 2010: 5; Shi and Levy, 2005: 267).

In a bid to evaluate library services, libraries have continued to collect various service counts statistics such as 
the number of books borrowed or the number of reference questions asked, amongst others. According to Nitecki (1996: 182) and Shi and Levy (2005: 267) these kinds of statistics are not sufficient as they do not provide meaningful findings for improving services systematically. This traditional approach is also criticized as it is based on the perception of the libraries describing the occurrence of services and hence is not an objective approach. Effective evaluation of service quality is ensuring that the perspective of the user is considered. According to Sahu (2007: $235)$ quality is the ability to meet a stated need. Awan et al. (2008: 52) suggest that quality would be meaningless if customer satisfaction is not achieved.

The customer as the most important factor in service quality is advocated through the TQM philosophy which guides this article.

\section{Research methodology}

A descriptive non-experimental quantitative approach was used. A quantitative approach allowed comparison of the different variables. According to Creswell (2003: 7) a quantitative approach provides an objective reality of what is in existence. A survey design was used to provide "quantitative description of trends or opinions of a population by studying a sample of the population" (Creswell, 2009: 12). Through this design the quality of AKU library services was evaluated based on the satisfaction of users with these services and as expressed by and based on users' expectations and perceptions.

The population was defined as all registered library users of Aga Khan University. The population consisted of nursing and medical faculty; nursing and medical students. The registered members were as follows: nursing faculty $(n=16)$, nursing students $(n=63)$, medical faculty $(n=38)$, medical students $(n=63)$. The total population, $N=180$. Random sampling was used. Random sampling is a sampling technique whereby each individual has an equal probability of being selected and this ensures that the sample is representative of the population (Bless and Higson-Smith, 2000: 86; De Vos et al., 2004: 202; Mugenda and Mugenda, 2003: 45). According to Creswell (2003: 164) random sampling produces a sampling error that is as small as possible and also maximizes external validity. The sampling frame was obtained by generating a list of the population from the AKU library management system. To ensure that all user groups were represented, the heterogeneous population was stratified into homogeneous groups. This was done by dividing the sampling frame into homogenous subgroups (strata), i.e. medical students, medical faculty members, nursing students, nursing faculty members.

A sample size of 123 was calculated, and in order to determine proportional sample size for each stratum, the percentage each stratum should contribute was calculated as follows:
Table I. Sampling and sample size.

\begin{tabular}{lccc}
\hline Strata & Population & Percentage & Sample size \\
\hline Nursing faculty & 16 & 9 & 11 \\
Nursing student & 63 & 35 & 43 \\
Medical faculty & 38 & 21 & 26 \\
Medical student & 63 & 35 & 43 \\
TOTALS & 180 & 100 & 123 \\
\hline
\end{tabular}

$$
\frac{\mathrm{n}}{\mathrm{N}} \times 100
$$

(Where, $n=$ =population of the strata; $N=$ library users population)

Table 1 shows the population for each stratum, the percentage each stratum should contribute to the sample and the proportional sample size per stratum.

A close ended self-administered questionnaire also known as a structured questionnaire that provides the respondents with a choice of answers was used as the instrument of choice for data collection. The questionnaire which was on paper was administered by the author who is a librarian. The questionnaire used was an existing questionnaire called SERVQUAL which was developed by Parasuraman et al. (1988).

\section{Results and discussion}

The data was collected and entered in Microsoft Excel and analysis of the data was done with the assistance of an external statistician using the Statistical Package for Social Science (SPSS) version 17.0. Univariate analysis was applied to examine the characteristics of the 2 main variables; expectations and perceptions. This was to examine the distribution, central tendency and dispersion.

Of the total 123 participants in the sample size 78 completed and returned the questionnaire, i.e. a $63 \%$ response rate, which is considered sufficient in research in ensuring that the results are representative (Baruch and Holtom, 2008: 1148; Nulty, 2008: 308). Generally, there were more student respondents than faculty respondents (nursing students $=55.8 \%$; medical students $=14.3 \%$; nursing faculty $=10.4 \%$; medical faculty $=19.5 \%$ ) and this could be attributed to the number of students compared to the number of faculty members at AKU. The undergraduate nursing students however appeared more willing to participate in the study than the postgraduate medical student sample. This was also similar for the nursing faculty sample and medical faculty sample

\section{Gaps between users' perceptions and expectations}

One of the objectives was to determine the gaps between users' perceptions and expectations. Using the formula $G$ $=\mathrm{P}-\mathrm{E}$, the SERVQUAL questionnaire was based on the 
basic assumption that if a negative score is obtained this would mean that the performance is below expectations, translating into a low service quality perception. If a positive score is obtained this would mean that the performance exceeds expectation, translating into high service quality (Awan et al., 2008; Filiz, 2007; Jayasundara, 2011; Manjunatha and Shivalingaiah, 2004; Parasuraman et al., 1988; Robinson, 1999; Somaratna and Peiris (2011). SERVQUAL was therefore developed based on the notion that to deliver high quality service there should be no gap between the users' expectation and perceptions (Tuomi, 2001).

Table 2 shows the results of the service quality gap score for each service statement item. The gap scores have been arranged from the largest to the smallest in order to easily identify the largest positive gap and largest negative gap.

Results from this table show 11 service statement items that have a positive score, and 18 service quality statements with a negative score. Those that are negatively marked indicate the service statements that do not meet the expectations of the respondents and hence low service quality.

Since the negative gaps are arranged from the smallest to the largest in Table 2, the largest gaps of service quality statements are thus easy to identify. Though 18 service quality statements have a negative gap we can identify the five service quality statements with the largest as follows:

1. Library staff provide services accurately with minimum interruption, i.e. reliability (gap $=-0.37$ ).

2. Library facilities are visually appealing, such as computer, audio-visual, i.e. tangibles ( $\mathrm{gap}=-0.31$ ).

3. Library staff understand the needs of the users, i.e. empathy $($ gap $=-0.21)$.

4. Library materials (such as brochures, statements or signs) associated with services are visually appealing, i.e. tangibles (gap $=-.0 .20)$.

5. Library staff promptly serve users, i.e. responsiveness $($ gap $=-0.20)$

The above findings may provide an indication of service areas that AKU library needs to improve as these service areas had one of the largest negative scores translating into low service quality.

\section{Paired perceptions and expectations means for the service quality dimensions}

In order to see whether there are gaps between the respondents' expectations and perceptions, paired t tests analysis was conducted and results presented in Table 3 . The paired sample t-test generally compares the mean of two variables. Table 3 pairs the respondents' mean for the two variables expectations and perceptions for each dimension.
Table 2. Service quality gaps by item.

Service quality statements for the various attributes

Library staff are always willing to respond to users' questions

Library staff are always courteous

It is easy to make compliments, complaints or suggestions about services

Library staff provide services in a timely manner

Library provides space that enables quiet and calm study

Library staff are knowledgeable in answering user queries

Physical condition of resources in collection is good

Library staff keep users informed about when services will be performed

Library online catalogue is easy to understand Convenient access to library collections

Required resources are available

Library staff give individual attention to the users

Resources are delivered in a timely manner

The library is comfortable and is in a good

location

Library website contains necessary information

Library staff provide services as promised

Giving priority to the users' interests

Convenient opening and closing hours

Library staff are willing to help users

Equipment in the library is modern and in good condition

Library staff deal with users in a considerate manner

Assuring users of accuracy and confidentiality of their personal information

Digital or online materials can be accessed from computers

Information from library meets users' needs

Library staff promptly serve users

Library materials (such as brochures,

statements or signs) associated with services are visually appealing

Library staff understand the needs of the users Library facilities are visually appealing (such as computer, audio-visual)

Library staff provide services accurately with minimum interruption

N Gap

76

0.29

77

0.25

77

(7)

The results in Table 3 reveal that there is a slight difference between the expectation mean and perception mean whereby the expectation mean of most dimensions is slightly higher than the perception mean. Therefore, in line with the gap theory, since the respondents' expectations are higher or rather greater than their perceptions this is an indication that there is a service quality gap in the AKU library services (Lin et al., 2009). 
Table 3. Paired dimensions means for users' perceptions and expectations.

\begin{tabular}{|c|c|c|c|c|}
\hline & & Mean & $N$ & Std. Deviation \\
\hline \multirow[t]{2}{*}{ Pair I } & Assurance expectation mean & 5.902 & 77 & I.195I \\
\hline & Assurance perception mean & 5.873 & 77 & I.1804 \\
\hline \multirow[t]{2}{*}{ Pair 2} & Collection and access expectation mean & 5.958 & 77 & 1.1350 \\
\hline & Collection and access perception mean & 5.926 & 77 & I. 1588 \\
\hline \multirow[t]{2}{*}{ Pair 3} & Empathy expectation mean & 5.884 & 76 & 1.2356 \\
\hline & Empathy perception mean & 5.835 & 76 & I.226I \\
\hline \multirow[t]{2}{*}{ Pair 4} & Library as a place expectation mean & 5.907 & 75 & 1.4206 \\
\hline & Library as place perception mean & 5.847 & 75 & 1.3901 \\
\hline \multirow[t]{2}{*}{ Pair 5} & Reliability expectation mean & 5.980 & 75 & I. 1246 \\
\hline & Reliability perception mean & 5.877 & 75 & I.167I \\
\hline \multirow[t]{2}{*}{ Pair 6} & Responsiveness expectation mean & 6.046 & 76 & 1.2501 \\
\hline & Responsiveness perception mean & 5.967 & 76 & 1.2405 \\
\hline \multirow[t]{2}{*}{ Pair 7} & Tangibles expectation mean & 5.662 & 76 & 1.3305 \\
\hline & Tangibles perception mean & 5.618 & 76 & 1.3027 \\
\hline
\end{tabular}

\section{Variables that determine users' perceptions and expectations of AKU library service quality}

The AKU library users were required to indicate what library services they expect or rather feel that AKU library should provide or possess, i.e. their expectations. The users were also required to indicate the extent to which they believed AKU library already provides the services, i.e. their perception. The respondents were provided with a questionnaire that had 30 service quality statements under the following seven variables: assurance, collection \& access, empathy, library as place, reliability, responsiveness and tangibles. Since the questionnaire was divided into a section for expectation and another for perception, the same 30 service quality statements under the aforementioned variables appeared in both the expectation and perception sections. The respondents were to rate each statement on a Likert scale of 1 to 7 whereby 1 implied that the respondent strongly disagrees and 7 implied that the respondent strongly agrees to the statement in order to show the extent of their expectation of AKU library as well as their perception of AKU library.

Generally the respondents gave a rating of 6 and 7 for the service quality statements for both expectations and perceptions; with a majority of respondents indicating a rate of 7. This means that the majority of the respondents strongly agreed with most of the service quality statements in view of what they expect AKU library should possess as well as the services that already exist at AKU library. Verbal qualifiers were assigned for the Likert Scale rates for ease of data analysis as well as for ease of explanation. The verbal qualifier assigned for 6 on the Likert Scale was the term "agreed" while the qualifier for 7 was the term "strongly agreed". Hence it can be stated that the expectations and perceptions of most AKU library users was between those who agree and those who strongly agree. This can be expounded further to mean that most AKU library users either agree or strongly agree AKU library should possess all the service qualities under the provided variables. In addition most AKU library users also agree or strongly agree that AKU library already possesses the features or services indicated.

According to the findings therefore, AKU library users perceive the aforementioned seven service quality variables as important features of a library. The findings also indicate that AKU library has made considerable effort towards meeting the expectations of its users. This indication of the considerable effort of AKU library is represented by the mode and the mean of AKU library users' perception as analysed in the findings.

\section{Variables of service quality that meet or exceed AKU library users' expectations}

With regards to AKU library users' expectations of AKU library services, the results show 12 service quality statements that score a mean rate between 6 and 6.16 while the users' perceptions indicate three service quality statements that score a mean rate between 6 and 6.03. A mean of 6 can be verbally translated to mean that AKU library users generally agree with the majority of the service statements in regards to their expectations and perceptions of AKU library services. Notably the perception mean rates of the AKU library users are not as high as the AKU library users' expectations mean rate. The three service quality statements that have the highest mean rate can be interpreted to mean that these are the service areas at AKU library that meet or exceed the expectations of its users. These services are as follows:

1. Library staff provide services in a timely manner - reliability.

2. Digital online materials can be accessed from a computer - collection \& access. 
3. Resources are delivered in a timely manner - collection \& access.

From the above three quality service statements it can be extrapolated that the service quality variables that meet or exceed AKU library users' expectations are the reliability and collection and access of AKU library services. In addition we can arguably state that these are the variables AKU library users find most important. Collection and access, as well as reliability are indisputably very important services in an academic setting such as AKU. Furthermore, being predominantly a healthcare education institution, it is no wonder that the users of AKU expect the collection to be available in a timely manner. In addition, due to the fact that teaching at $\mathrm{AKU}$ is a combination of classroom teaching and sessions in the clinical setting, the access of information from computers is evidently important as this enables the students and faculty to have access to information at all time. This therefore ensures that access to information is not limited to the opening hours of the physical library. Notably the findings are similar to various other studies that showed reliability as being the dimension that is considered the most important by users when evaluating the quality of library services (Shoeb and Ahmed, 2009).

\section{Services at AKU library that fall short of users' expectations}

Services that fall short of the users' expectations can be interpreted as those services with the lowest perception mean. This is because, as earlier mentioned, perception is seen as how well AKU library provides services in view of the users' expectation. The five service quality statements with the lowest perception mean as revealed in the findings are as follows:

1. Library facilities are visually appealing (such as computers, audio visual) - tangibles.

2. Library online catalogue is easy to understand collection \& access.

3. Equipment in the library is modern and in good condition - tangibles.

4. Convenient opening and closing hours - collection $\&$ access.

5. Library material (such as brochures, statements or signs) associated with services are visually appealing - tangibles.

From the above five quality service statements one can extrapolate that the tangible attribute as well as the collection and access attribute are the service quality attributes that fall short of AKU library users' expectations. It is interesting to note that the collection and access attribute are also indicated as a variable that meets or exceeds the users' expectations. Though collection and access also appear as an attribute that meets the expectations of the AKU library users, it shows that not all service quality statement items under the collection and access variable meet their needs. This is therefore an indication that there is still need for improvement within the collection and access of the AKU library services. Hence AKU library should critically review all the service quality statement items which are part of the collection and access variable and ensure those that fall short of the users' expectations are addressed. Those that are identified as falling short of the library users' expectations are the online library catalogue which users perceive to be difficult to understand and the library opening hours which users feel are not convenient. In addition, the AKU library needs to review the facilities and equipment as the findings identify these as not being appealing and in good condition.

It is also interesting to note that out of the five service quality items with the lowest perception mean, three are service items referring to the tangibles attribute. Hence extrapolating from the findings it is evident that the tangibles of AKU library fall short of its users' expectations.

Notably, the one case study by Nitecki (1996) using SERVQUAL shows consistency in what users consider to be important when evaluating service. In this study, tangibles were found least important while reliability were perceived to be most important.

\section{Gaps between AKU library users' expectations and perceptions of AKU library service quality}

The findings reveal that more service quality statements have a negative score than a positive score. This means that there are more service qualities at AKU library that do not meet the expectations of its users. As mentioned above, the SERVQUAL questionnaire was developed on the notion that to deliver high quality service there should be no gap between the users' expectations and perceptions (Tuomi, 2001). A positive score means that the library service provided is of high quality while a negative score means that the service is of low quality (Jayasundara, 2011; Somaratna and Peiris, 2011). Out of the 30 service quality statements 18 have a negative score and this is a large number of items. Only one service quality statement item has no gap, namely: required resources are available.

Since it is important for any library to ensure that it meets the users' expectations by providing high quality service, the findings reveal the service quality statements with the highest gaps as follows:

1. Library staff provide services accurately with minimum interruption, i.e. reliability (gap $=-0.37)$.

2. Library facilities are visually appealing; such as computer, audiovisual, i.e. tangibles ( $g a p=-0.31$ ).

3. Library staff understand the needs of the users, i.e. empathy (gap $=-0.21)$. 
4. Library materials (such as brochures, statements or signs) associated with services are visually appealing, i.e. tangibles (gap $=-.0 .20$ ).

5. Library staff promptly serve users, i.e. responsiveness (gap $=-0.20)$

The above mentioned five service quality statements suggest that the service quality attributes with the largest gaps at AKU library are: reliability, tangibles, empathy and responsiveness. The findings found the reliability attribute, especially with regards to the provision of library services accurately by the AKU library staff, has the highest gap score. The negative gap score for the said service is -0.37 . Notably other AKU library services with a negative gap score that are associated with library staff and the provision of library services are services within the empathy attribute and responsiveness attribute. Within the empathy attribute there was a negative score of $0.21(-0.21)$ with regards to AKU library staff understanding the needs of the users. With regards to the responsiveness attribute the findings show a negative score, that is -.20 , in the service statement that sought to find out how prompt AKU library staff are when serving users.

These findings at AKU library are notably consistent with those of Nagata et al. (2004) carried out in England, Finland and Japan, as well as the study by Ahmed and Shoeb (2009) carried out in Bangladesh, where the largest gaps are those service quality items related to the library collection and items related to staff. In these studies, the main problems are mainly related to "reading resources, poor quality of services by library staff and lack of modern equipment" (Ahmed and Shoeb, 2009: 30).

In addition, the findings at AKU library reveal that the tangibles, facilities and equipment such as computers, as well as the publicity material such as brochures and signage fall short of the library users' expectations. The AKU library findings identify these tangibles as having one of the highest gaps, that is, -0.31 . The service with a high negative score under the tangible attribute is that related to the library's equipment and facilities, suggesting that users do not appear to find them appealing. This is therefore one service area that the AKU library should review and attempt to identify the best way to improve in order to meet the needs of its users. From the findings, the suggestion is "this may be an indicator of the library having not invested in physical facilities, equipment, etc.". This suggestion is similar to one provided by the study by Tuomi (2001) that found the tangibles as having the highest service quality gap. Some of the problems that may be identified with equipment such as computers may include speed, bandwidth and the number of computers available for users. With regards to physical facilities the service quality gap may have been as a result of inadequate space for different activities, for example the lack of adequate discussion rooms for users in the library.
Academic libraries striving towards improving their services should use appropriate, standardized and userbased tools when evaluating the quality of the services they provide. This is because libraries in an academic environment play a major role in the provision of information and services towards the support of students and faculty academic and research needs. The information era has tremendously changed as a result of a rapid growth of information as well as a change in user behaviour and hence libraries need to objectively evaluate the services they provide so as to ensure that they meet the needs of the users. Libraries therefore need to be evaluated with regards to how they offer various services as opposed to simply what services they offer to users. The need for appropriate evaluation of library service quality is in line with various studies that have indicated that libraries have for a long time used inadequate methods of evaluating quality such as the collection size, opening hours among others. Perhaps user-based assessment tools can be used in addition to the aforementioned methods.

Due to the complexity of evaluating quality, it is then important for the library to identify an appropriate method of ensuring service quality is realized. The findings have demonstrated that it is useful for libraries to adopt a TQM methodology in evaluating the quality of their services. This is because the philosophy is founded on the need to ensure that library users' needs are identified and subsequently satisfied. Based on this aspect of identifying the needs of the users it is essential to apply a user-based assessment tool such as SERVQUAL. This was a very useful tool in evaluating the quality of AKU library services with a view to identifying the expectations and perceptions of AKU library users as well as the gaps in the services provided by the library. It may subsequently enable the AKU library staff to identify areas that require improvement. Since each service quality attribute has a number of services aligned to it, it is important to identify the exact service that shows a gap between the users' expectation and the users' perceptions. For example, as mentioned earlier the highest gap at AKU library is the reliability attribute but specifically with regards to the way the library staff provides services accurately and with minimum interruption. In this context it is therefore acceptable to indicate that the identification of users' needs and expectations is essential to better understand their needs and subsequently respond to them through the provision of quality services.

It is evident from the findings that although the Aga Khan University library has been carrying out sporadic surveys in an attempt to evaluate the quality of its services, the library has yet to comprehensively meet the expectations of the users. This is apparent from the gaps between the library users' expectations and perceptions as revealed by the findings. The gaps in the quality of AKU library services may also be attributed to the inadequate methods the library has been using over the years in evaluating its 
service quality and these methods have not effectively identified the service gaps. The inadequate methods being referred to are primarily the input-based methods whereby the AKU library attempts to evaluate the quality of its services by number of books, opening hours and circulation, among others. In addition, there is no evidence that the library carried out a survey using a user-based assessment tool such as SERVQUAL. While trying to remain competitive and relevant in a challenging environment it is therefore important that the AKU library ensures it identifies the users' perceptions and users' expectations of its services in order to identify the needs of the users and work towards meeting these needs.

In addition the analysis also sought to evaluate the gaps between the users' expectations and perceptions with the basic assumption that, if a negative score is obtained this would mean that the service delivery is below the expectation of the users and a positive score would mean that the service delivery exceeds the expectations of the users. Since the findings found more services with a negative score than those with a positive score, this means that there are more services at AKU library that do not meet the expectations of its users than those that do. This is evidently a clear indication that a lot more effort is required towards meeting the expectations of AKU library users and subsequently in ensuring quality service at the AKU library. This is because the SERVQUAL instrument used was developed based on the notion that to deliver high quality service there should be no gap between the users' expectation and perception.

From the findings, AKU library should give priority to improving services related to its reliability, tangibles, empathy and responsiveness attributes. According to the findings, the specific services that need to receive priority in order to meet the expectations of the users and subsequently provide quality services are those services related to the library collection as well as staff-related service items. The findings show that "a consumer's overall service quality is the accumulation of multiple experiences" (Sharma et al., 2010: 3) as well as a "multi-faceted concept" (Somaratna and Peiris, 2011) and hence it is important to standardize the tasks and behaviours being performed within the library. This is notably as a result of the transformation in the information industry characterized by changing paradigms in the provision of library services as well as changing user behaviour. The transformation in the information industry thus requires the library to adapt to these various changes as a way of ensuring provision of quality services.

\section{Conclusion and recommendations}

The findings will hopefully help the AKU library management in identifying its strengths and weaknesses as it strives to meet the needs of AKU library users through the provision of quality services. Identifying its strengths and weaknesses is important at a time where there is anticipated growth of the institution. AKU has continued to experience a growth in the number of students as well as academic programmes and in view of this anticipated expansion the AKU library has to definitely align itself to the quality expectations and ensure that it provides services that meet the expectations of the library users.

The following recommendations are made:

- Kenyan academic libraries need to adopt user-based assessment tools in the evaluation of service quality as opposed to input-based evaluation methods. It is noted that academic libraries in Kenya adhere to standards outlined by the CUE and these are the standards that the academic libraries in Kenya use in evaluating the quality of their library services. Since these are the standards that academic libraries in Kenya have been adhering to, the recommendation is that such statutory bodies incorporate standardized user-based assessment tools for the evaluation of library service quality.

- The adoption of TQM philosophy in ensuring continuous assessment of the service quality of academic libraries in Kenya. The importance and significance for continuous assessment and improvement in academic libraries in Kenya has also been emphasized in a study by Odera-Kwach (2011: 237) in which the author similarly recommends that CUE "consider the introduction of systematic quality indicators and develop a culture of quality to provide for the measurement and monitoring of continuous improvement in universities libraries in Kenya". The culture of continuous improvement and evaluation of service quality in academic libraries can be realized through the application of quality management principles. TQM for example is one such management philosophy that advocates for continuous improvement and hence resulting to service quality.

- The use of SERVQUAL at AKU library as well as the other academic libraries in Kenya as an instrument which would assist decision makers in directing energies to the right areas in an attempt to improve the services. Data from a survey using SERVQUAL can suggest priority areas with problems that AKU library needs to address. Such data can also assist in identifying service quality gaps which may be arising from staff assumptions of what users like as well as identify services offered in a manner that does not meet users' needs (Nitecki, 1996). The use of an instrument such as SERVQUAL can also be justified because the most important aspect of quality service is identifying the expectations of the users (Brysland and Curry, 2001). However, due to the generic nature of the 
SERVQUAL evaluation tool, it is further recommended that the tool should be used on a regular basis for comparative purposes (Brysland and Curry, 2001; Shahin, 2006). This means that the SERVQUAL instrument should be administered repeatedly in order to ascertain the true picture of service quality. Studies have shown that the expectations and perceptions of users of a service may change following the long use of the service. It is also necessary to use this tool on a regular basis because the level of the services provided may change and the user expectations may also change. It is also recommended that there is need to use SERVQUAL in other academic libraries in Kenya for further comparison and also for the purpose of contributing to the knowledge of research using SERVQUAL from academic libraries in developing countries.

In line with the findings, the recommendation is that, in order to reduce the large gaps in the service areas relating to AKU library staff, the AKU library management should consider providing more training to staff to enhance their customer service skills. The training should specifically have more focus on how to handle the different users and how to be courteous as well as more caring to the user. Furthermore, AKU library management should develop ways of reducing the turnaround time when providing user services in an effort to improve and provide faster and reliable services.

The findings suggest that AKU library may have not invested in the physical facilities, equipment, etc. and hence the recommendation is that there is need to provide adequate facilities for its users such as group discussion rooms. Furthermore, AKU library should continuously upgrade its equipment such as computers and this may be achieved by ensuring that purchase of new computers is a continuous exercise. The AKU library should also work closely with the Information Technology (IT) department to ensure that adequate bandwidth is available for easy and quick access to the information available online.

\section{Further research}

The findings reveal that the perceptions and expectations of the student population that uses the AKU library services are higher than that of the faculty population that uses the AKU library services. Although the difference was small, further research is recommended to investigate the reasons why the student population seems to have a higher expectation and perception of AKU library services than the faculty population. Further research could be in the form of qualitative research approach whereby indepth data can be collected using open-ended questionnaires or interviews in order to gain further understanding as to why the expectations and perceptions of the student population at AKU library are higher.
The findings reveal that it is important for libraries to apply averred management principles and philosophies such as TQM to ensure service quality vis-à-vis customer satisfaction. Through this article it was identified that the TQM philosophy involves a wide range of aspects; however, studying the whole range is beyond the scope of any one study. Hence further research is recommended to investigate how other aspects of a management principle such as TQM can be applied to improve the quality of AKU library services.

Since the investigation was limited to one academic library the findings therefore may not necessarily be generalized to other academic libraries in Kenya. The findings based at AKU library can however form the foundation for further research in other academic libraries in Kenya. Further research is therefore recommended to investigate service quality using user-based assessment tools such as SERVQUAL in other academic libraries in Kenya. This will provide more conclusive information that can be used in a developing country like Kenya in regards to the evaluation of library service quality.

\section{Declaration of Conflicting Interests}

The author(s) declared no potential conflicts of interest with respect to the research, authorship, and/or publication of this article.

\section{Funding}

The author(s) received no financial support for the research, authorship, and/or publication of this article.

\section{References}

Aga Khan Development Network (2007) AKU in East Africa. Available at: http://www.akdn.org/aku_east_africa.asp (accessed 14 January 2013).

Aga Khan University Library (2011) Usage of Information Resources at $A K U$ : Survey Report. Nairobi: Aga Khan University Library.

Ahmed SMZ and Shoeb ZH (2009) Measuring service quality of a public university library in Bangladesh using SERVQUAL. Performance Measurement and Metrics 10(1): 17-32.

Alemna AA (2001) The need for marketing and total quality management strategies in libraries in Ghana. INSPEL 35(4): 265-269.

Awan M, Azam S and Asif M (2008) Library service quality assessment. Journal of Quality and Technology Management 4: 51-64.

Babbie E and Mouton J (2001) The Practice of Social Research. Cape Town: Oxford University Press.

Baruch Y and Holtom BC (2008) Survey response rate levels and trends on organizational research. Human Relations 61(8): 1139-1160.

Besterfield DH, Besterfield-Michna C, Besterfield G, et al. (2003) Total Quality Management. 3rd edn. Upper Saddle River, NJ: Prentice Hall.

Bless C and Higson-Smith C (2000) Fundamentals of Social Research Methods: An African Perspective. Cape Town: Juta Education. 
Brysland A and Curry A (2001) Service improvements in public services using SERVQUAL. Managing Service Quality 11(6): 389-401.

Carman JM (1990) Consumer perceptions of service quality: An assessment of the SERVQUAL dimensions. Journal of Retailing 66(1): 33-55.

Commission for University Education (2013) Standards and Guidelines for UniversityLibraries in Kenya.Available at:http:// www.cue.or.ke/images/phocadownload/UNIVERSITIES\%20 STANDARDS\%20AND\%20GUIDELINES\%20June \%20 2014.pdf (accessed 5 January 2015).

Creswell J (2003) Research Design: Qualitative, Quantitative, and Mixed Methods Approaches. London: SAGE.

Creswell J (2009) Research Design: Qualitative, Quantitative, and Mixed Methods Approaches. 3rd edn. London: SAGE.

Crossno J, et al. (2001) Assessment of customer service in academic health care libraries (ACSAHL): An instrument for measuring customer service. Bulletin of Medical Library Association 89: 170-176.

De Vos AE, Strydom H, Fouche C, et al. (2004) Research at Grass Roots: For the Social Sciences and Human Service Professions. Pretoria: Van Schaik.

Derfert-Wolf L, Gorski M and Marcinek M (2005) Quality of academic libraries-funding bodies, librarians and users perspective: A common project of Polish research libraries on comparable measures. In: World library and information congress: 71th IFLA general conference and council, Oslo, Norway, 14-18 August 2005.

Filiz Z (2007) Service Quality of University Library: A Survey amongst Students at Osmangazi University and Anadolu University. Available at: http://eidergisi.istanbul.edu.tr/ sayi5/iueis5m1.pdf (accessed 18 March 2013).

Ho SKM (1995) Is the ISO 9000 series for total quality management? International Journal of Physical Distribution \& Logistics Management 25(1): 51-66.

Jayasundra CC (2011) A modular approach to customer satisfaction in relation to service quality. Journal of the University Librarians' Association of Sri Lanka 15(1): 23-82.

Kavulya JM (2006) Trends in funding of university libraries in Kenya: A survey. The Bottom Line: Managing Library Finances 19(1): 22-30.

Khurshid Z (1997) The application of TQM in cataloguing. Library Management 18(6): 274-279.

Kiran K (2010) Service quality and customer satisfaction in academic libraries: Perspectives from a Malaysian university. Library Review 59(4): 261-273.

Kujala J (2002) Total quality management as cultural phenomena: A conceptual model and empirical illustration. Doctor of Technology Dissertation, Helsinki University of Technology, Finland.

Kumbar RD (2004) The importance of marketing and total quality management in libraries. Electronic Journal of Academic and Special Librarianship 5(2/3). Available at: http://southernlibrarianship.icaap.org/content/v05n02/kumbar_r01.htm (accessed 12 September 2007).

Ladhari R (2008) Alternative measures of service quality: A review. Managing Service Quality 18: 65-86.

Lee H, Lee Y and Yoo D (2000) The determinants of perceived service quality and its relationship with satisfaction. Journal of Services Marketing 14(3): 217-231.
Lincoln YS (2002) Insights into library services and users from qualitative research. Library \& Information Science Research 24(1): 3-16.

Ling-Yun Y and Hai-Kang Z (2005) An experiment on digital library based on the method of TQM system. Journal of Zhejiang University Science 6A(11): 1362-1366.

Manjunatha K and Shivalingaiah D (2004) Customer's perception of service quality in libraries. Annals of Library and Information Studies 51(4): 145-151.

Mehra S and Ranganathan S (2008) Implementing total quality management with focus on enhancing customer satisfaction. International Journal of Quality \& Reliability Management 25(9): 913-927.

Mehra S, Hoffman JM and Sirias D (2001) TQM as a management strategy for the next millennia. International Journal of Operations \& Production Management 51(5/6): 855-876.

Moghaddam GG and Moballeghi M (2008) Total quality management in library and information sectors. The Electronic Library 26(6): 912-922.

Morrow PC (1997) The measurement of TQM principles and work-related outcomes. Journal of Organisation Behaviour 18(4): 363-376.

Mugenda OM and Mugenda AG (2003) Research Methods: Quantitative and Qualitative Approaches. Nairobi: ACTS Press.

Nagata H, Satoh Y, Gerrard S, et al. (2004) The dimensions that construct the evaluation of service quality in academic libraries. Performance Measurements and Metrics 5(2): 53-65.

Nitecki DA (1996) Changing the concept and measure of service quality in academic libraries. Journal of Academic Librarianship 22(3): 181-190.

Nulty DD (2008) The adequacy of response rates to online and paper survey: What can be done? Assessment \& Evaluation in Higher Education 28(3): 301-314.

Odera-Kwach BA (2011) The impact of external quality assurance on university libraries in Kenya. PhD Dissertation, University of South Africa. Available at: http://uir.unisa. ac.za/bitstream/handle/10500/5025/dissertation_kwach_b. pdf?sequence $=1$ (accessed 15 November 2016).

Ondari-Okemwa E (2000) Training needs of practising professional librarians in the Kenyan public university libraries: A critical analysis. Library Management 21(5): 257-268.

O'Neill M, Wright C and Fitz F (2001) Quality evaluation in online service environments: An application of the importance-performance measurement technique. Managing Service Quality 11: 402-417.

Parasuraman A, Zeithaml VA and Berry LL (1985) A conceptual model of service quality and its implications for future research. Journal of Marketing 49(4): 41-50.

Parasuraman A, Zeithaml VA and Berry LL (1988) SERVQUAL: A multi-item scale for measuring consumer perceptions of service quality. Journal of Retailing 64(1): 12-40.

Peters VJ (1999) Total service quality management. Managing Service Quality 29(1): 6-12.

Pilling S (1996) Putting the customer first: Total quality and customer service at the British Library Document Supply Centre. Interlending \& Document Supply 24(2): 11-16.

Powell TC (1995) Total quality management as competitive advantage: A review and empirical study. Strategic Management Journal 16: 15-37.

Research Information Network (2010) Challenges for Academic Libraries in Difficult Economic Times: A Guide for Senior 
Institutional Managers and Policy Makers. Available at: www.rin.ac.uk/challenges-for-libraries (accessed 14 January 2013).

Robinson S (1999) Measuring service quality: Current thinking and future requirements. Marketing Intelligence \& Planning 17(1): 21-32.

Sahu AK (2007) Measuring service quality in an academic library: An Indian case study. Library Review 56(3): 234-243.

Seth N, Deshmukh SG and Vrat P (2005) Service quality models: A review. International Journal of Quality \& Reliability Management 22(9): 913-949.

Shahin A (2006) SERVQUAL and Model of Service Quality Gaps: A Framework for Determining and Prioritizing Critical Factors in Developing Quality Services. Available at: http://www.proserv.nu/b/Docs/Servqual.pdf (accessed 15 November 2016).

Sharma SK, Anand VK and Sharma G (2010) Quality of services rendered by university libraries: An empirical investigation. TRIM V 6(1): 1-16.

Shi X and Levy S (2005) A theory-guided approach to library services assessment 1. College \& Research Libraries 66(3): 266-277.

Shoeb Z and Ahmed S (2009) Individual differences in service quality assessment: A study of a private university library system in Bangladesh. Performance Measurement and Metrics 10: 193-211.

Somaratna SD and Peiris CN (2011) Service quality in University of Colombo libraries: An assessment. Annals of Library and Information Studies 58 (June): 1-18.

Stark J (1998) A Few Words about TQM. Available at: http:// www.johnstark.com/fwtqm.html (accessed 2 April 2010).

Tam LWH (2000) Quality management theory and practice: Some observations of practices in Australian academic libraries. Library Management 21(7): 349-356.

Tuomi V (2001) Quality of academic library service: A customer's point of view. Available at: http://soc.kuleuven. be/io/egpa/qual/vaasa/paper_vaasa_tuomi.pdf (accessed 12 September 2007).
Wang H (2006) From 'user' to 'customer': TQM in academic libraries? Library Management 27(9): 606-620. Available at: http://www.emeraldinsight.com/0143-5124.htm (accessed 12 September 2007).

Whitlatch JB (2003) Reference futures: Outsourcing, the web, or knowledge counselling. Reference Services Review 31(1): 26-30.

Yu L, et al. (2008) An epistemological critique of gap theory based library assessment: The case of SERVQUAL. Journal of Documentation 64(4): 511-551.

Zhan C and Zhang H (2006) How does a dandelion seed from overseas root and thrive? The successful implementation of TQM in Hainan University library. Library Management 29(6/7): 344-353.

\section{Author biographies}

Nasra Gathoni is the Faculty of Health Sciences Librarian (In-Charge) at the Aga Khan University, Nairobi campus. She holds a Master's Degree in Information Science from the University of South Africa (UNISA). She has 20 combined years' experience in library environment, 10 of this in an academic library. Nasra has presented papers on "health information" at various national, regional and international conferences. She received recognition for her role in promoting access to health information under the Research4Life "Unsung Heroes" Award. She has held a number of leadership roles such as President elect, Association for Health Information and Libraries in Africa (AHILA) for two terms.

Thomas van der Walt is a Professor in the Department of Information Science at the University of South Africa in Pretoria. He worked as a professional librarian in an embassy and university libraries for nine years before becoming a lecturer. Thomas has post graduate qualifications in Museum Science; Archival Science and Cultural History and did his doctorate on the portrayal of the Anglo Boer War in children's literature. He is the Editor of Mousaion: South African Journal for Information Studies and has published himself more than 60 articles in academic journals and and monographs. He teaches mostly at master's and doctoral level. 